\title{
Consumo Voluntário de Forragem de Três Cultivares de Panicum maximum sob Pastejo
}

\section{Valéria Pacheco Batista Euclides ${ }^{1}$, Luiz Roberto Lopes de S. Thiago², Manuel Claudio Motta Macedo ${ }^{3}$, Marcelo Paschoal de Oliveira ${ }^{4}$}

\begin{abstract}
RESUMO - Os objetivos deste trabalho foram estimar o consumo de matéria seca de animais pastejando três cultivares de Panicum maximum e relacioná-lo com ganho de peso, tempo de pastejo (TP) e algumas características químicas e estruturais do pasto. O delineamento experimental foi o de blocos casualizados com três tratamentos e três repetições. O consumo voluntário de matéria seca (CVMS) foi estimado em quatro ocasiões (maio, setembro, novembro e fevereiro). Para calcular a produção de fezes, foi usado o óxido crômico como marcador externo. Foram estimados a digestibilidade in situ da matéria seca e o tempo de pastejo, respectivamente, por intermédio de extrusas e tacógrafos. Foram estimadas as disponibilidades da forragem e dos componentes da planta. Apesar de os CVMS pelos animais terem sido semelhantes entre as cultivares, foram observadas maiores diferenças nos ganhos de peso, para os animais pastejando o capim Tanzânia, seguidos daqueles pastejando os capins Colonião e Tobiatã. Diferenças também foram observadas entre as cultivares para TP, que foi menor para os animais em pasto de Tobiatã, quando comparados aos que pastejaram as outras duas cultivares. O aumento no TP observado durante o período da seca não foi suficiente para impedir queda no consumo de forragem neste período. O CVMS foi correlacionado $\left(\mathrm{r}^{2}=0,77\right)$ com ganho diário de peso. As características estruturais das pastagens, disponibilidade de folhas e relação material verde:material morto, influenciaram mais o CVMS, ganho de peso diário e TP que os valores nutritivos das mesmas.
\end{abstract}

Palavras-chave: Cerrado, colonião, disponibilidade de forragem, ganho de peso diário, tempo de pastejo, valor nutritivo

\section{Voluntary Intake of Three Cultivars of Panicum maximum under Grazing}

\begin{abstract}
The objectives of this work were to estimate the dry matter intake by animals grazing three cultivars of Panicum maximum, and to relate it to live weight gain, grazing time (GT) and some structural and chemical characteristics of the pastures. The experimental design was the randomized block with three treatments and three replicates. The dry matter voluntary intake (DMVI) was estimated in four periods (May, September, November and February). Fecal output was measured using chromic oxide as an external marker. In situ dry matter digestibility was estimated from extrusa obtained by esophageal fistulated animals, and grazing time was registered by vibracorders. Also, forage availability and plant components were estimated. Greater differences in live weight gains were observed, for the animals grazing Tanzânia followed by those grazing Colonião and Tobiatã, although DMVI among cultivars were similar. There were also smaller differences among cultivars for the GT for animals grazing Tobiatã as compared to those grazing the other two cultivars. The increase in the GT observed during the dry season was not enough to avoid a decrease in the forage intake, during the same period. The VIDM was highly correlated $\left(r^{2}=0.77\right)$ with daily live weight gains. Structural characteristics of the forages, leaf availability and green matter:dead matter ratio, affected more the VIDM, daily weight gain and GT than their nutritive value.
\end{abstract}

Key Words: Brazilian savannas, guineagrass, forage availability, daily weight gain, grazing time, nutritive value

\section{Introdução}

O consumo de nutrientes digestíveis é o produto da quantidade de forragem consumida pela digestibilidade dos nutrientes nessa forragem. Entretanto, 60 a $90 \%$ das variações na qualidade potencial entre forrageiras são atribuídos às diferenças em consumo, enquanto 10 a $40 \%$, às diferenças em digestibilidades dos nutrientes (MERTENS, 1994).
De fato, MINSON (1971), comparando seis gramíneas do gênero Panicum, no mesmo estádio de desenvolvimento, encontrou diferenças na digestibilidade de apenas três unidades percentuais, ao passo que as referentes ao consumo voluntário foram de $37 \%$. Dessa forma, entre as características das forrageiras, as de maior importância são aquelas que determinam o seu consumo voluntário.

Os valores de consumo medidos com animais em

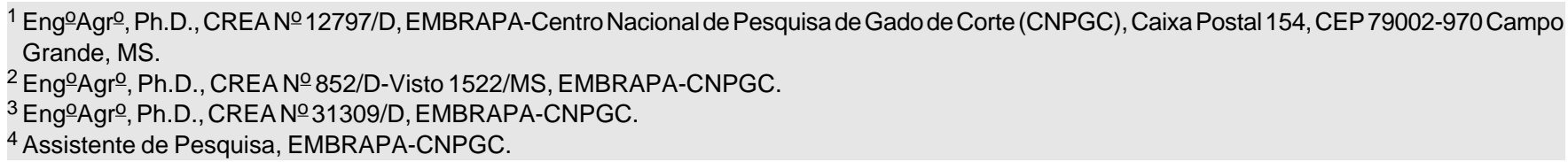


baias demonstram diferenças relativas e podem servir como guia da quantidade total que seria ingerida voluntariamente pelo animal. Contudo, esses valores podem ser pouco relacionados com o consumo de um animal em pastejo, em que fatores adicionais podem influenciar o consumo e a facilidade com que o animal apreende a forragem. Segundo COSGROVE (1997), o desempenho animal apresenta dependência direta do consumo diário de forragem e indireta dos efeitos do processo de pastejo sobre a composição da forragem, estrutura do relvado e produtividade da pastagem.

O Panicum maximum cv. Colonião já foi o capim mais utilizado para engorda de bovinos e um dos mais expressivos em extensão de área de pastagem cultivada. No entanto, apesar de o capim-colonião contribuir para maior ganho de peso por animal, sua baixa adaptabilidade a solos de baixa fertilidade e a sua baixa tolerância à seca fizeram com que ele fosse substituído por outras gramíneas menos produtivas, porém mais adaptadas a estas condições. Recentemente, como resultado da busca por maior produtividade e eficiência, vem aumentando o interesse pela utilização de P. maximum, principalmente das cultivares Tanzânia e Tobiatã, que se mostram mais adaptadas aos solos de média fertilidade, apresentam maior facilidade de manejo e respondem melhor à fertilização que a cv. Colonião (EUCLIDES et al. 1993, 1997).

Apesar dos trabalhos conduzidos, no Brasil, com forrageiras tropicais em pastejo, as informações quanto ao seus consumos são escassas. Dessa forma, os objetivos deste trabalho foram estimar o consumo de matéria seca de animais pastejando três cultivares de Panicum maximum e relacioná-lo com ganho de peso, tempo de pastejo e algumas características químicas e estruturais das pastagens.

\section{Material e Métodos}

Este experimento foi conduzido no Centro Nacional de Pesquisa de Gado de Corte (CNPGC), da Empresa Brasileira de Pesquisa Agropecuária (EMBRAPA), Campo Grande, MS em solo da classe Latossolo Vermelho Escuro álico - fase Cerradão, caracterizado por textura argilosa, $\mathrm{pH}$ ácido, baixa saturação por bases, alta concentração de alumínio e baixo teor de fósforo. O padrão climático da região é descrito, segundo Köppen, na faixa de transição entre Cfa e Aw tropical úmido. A precipitação média anual é de $1560 \mathrm{~mm}$. Os meses de maio a setembro caracterizam a época seca ( $30 \%$ da precipitação anual).

Após a derrubada, limpeza e o preparo do solo, foram feitas correção e adubação, que consistiram de $1,0 \mathrm{t} / \mathrm{ha}$ de calcário dolomítico $(\mathrm{PRNT}=100 \%)$, $300 \mathrm{~kg} / \mathrm{ha}$ de superfosfato simples, $100 \mathrm{~kg} / \mathrm{ha}$ de cloreto de potássio e $40 \mathrm{~kg} / \mathrm{ha}$ de FTE BR-16. Em seguida, foram semeadas as três cultivares de $P$. maximum: Colonião, Tobiatã e Tanzânia.

$\mathrm{O}$ delineamento experimental foi o de blocos casualizados com três tratamentos e três repetições. $\mathrm{O}$ consumo foi estimado utilizando-se quatro novilhos por piquete, ou 12 por tratamento, exceto nas pastagens de capim-colonião durante o período seco, quando foram utilizados apenas nove novilhos por tratamento.

Os piquetes (1,5 ha) foram submetidos a pastejo contínuo, por três anos, antes de serem submetidos às avaliações constantes do presente trabalho. Cada piquete foi pastejado por três novilhos de sobreano, os quais foram escolhidos observando-se idade, peso e tratamento prévio. Em seguida, estes animais foram distribuídos nos piquetes, ao acaso, no início do período experimental, onde permaneceram por um ano. Para assegurar disponibilidades semelhantes de forragem (em torno de 2,0 t/ha de matéria seca) para todos os tratamentos, ao longo do tempo, animais adicionais foram colocados e removidos de cada piquete. As médias das taxas de lotação utilizadas durante os períodos seco e das águas, para cada cultivar, são apresentadas na Tabela 1 .

O consumo foi estimado em quatro ocasiões, sendo duas durante o período seco (maio e setembro) e duas no período das águas (novembro e fevereiro). Os pesos vivos médios dos animais foram de 230,260, 340 e $360 \mathrm{~kg}$, nos meses de setembro, janeiro, maio e novembro, respectivamente.

Para estimar a produção de fezes, foi utilizado o óxido crômico como marcador externo, o qual foi fornecido em cápsulas introduzidas via oral com auxílio de uma mangueira flexível, por 12 dias consecutivos, em duas doses $(5 \mathrm{~g})$ diárias, às 5 e 16 h. No oitavo dia de dosificação, iniciou-se a coleta de fezes, nos mesmos horários, durante cinco dias. As amostras de fezes foram agrupadas por novilho e horário de obtenção, sendo homogeneizadas e secas a $50^{\circ} \mathrm{C}$ durante 96 horas e, em seguida, moídas e analisadas para óxido crômico.

Em cada período em que o consumo foi estimado, além dos três animais testes, um animal extra foi colocado em cada piquete, com o objetivo de se avaliar o conteúdo ruminal. Após a estimativa do consumo, no $13^{\circ}$ e $14^{\circ} \stackrel{\mathrm{d}}{\mathrm{dia}}$, os animais foram observados durante todo o primeiro período de pastejo intensivo (aproximadamente entre às 5 e 10 h). Tão logo 
estes cessavam a ingestão voluntária, eram sacrificados e o conteúdo total do rúmen era retirado e pesado, homogeneizado numa betoneira e amostrados para a determinação de matéria seca (MS) e fibra detergente neutro (FDN).

Para amostrar a dieta selecionada pelos animais, foram utilizados seis novilhos fistulados no esôfago. Estes animais foram agrupados dois a dois, e a cada dia um par diferente de animais amostrava um dos piquetes, de maneira que os seis animais amostrassem todos os piquetes. Os animais não sofreram jejum e foram retirados dos piquetes aproximadamente às $5 \mathrm{~h}$, quando receberam as bolsas coletoras de amostras, e retornaram aos mesmos piquetes, onde pastejaram durante 30 a 40 minutos. Logo após a coleta das extrusas, os animais foram transferidos de piquetes. Como as amostragens foram realizadas em dias alternados, cada par de animais permaneceu em cada piquete por, aproximadamente, 48 horas antes da coleta de extrusa.

As extrusas foram homogeneizadas na própria bolsa de coleta e divididas em duas partes: uma para separação das frações da planta (folha, caule e material morto) e outra foi seca a $50^{\circ} \mathrm{C}$ durante 72 horas, moída e analisada para composição química e digestibilidade in situ da matéria seca (DISMS), por 96 horas.

Durante o período em que se procedeu à coleta de extrusa, registrou-se ainda, o tempo de pastejo. Para isso, foram utilizados dois animais testes por piquete, durante 72 horas, equipados de tacógrafos adaptados em buçais. Após este tempo, as cartelas registradoras foram retiradas e, com o auxílio de um taquímetro, os minutos de pastejo por 24 horas foram computados.

As taxas de lotação foram ajustadas a cada 28 dias. Para isso, nessa época, pesaram-se os animais e estimou-se a disponibilidade de forragem. Para isso, foram tomadas 50 amostras $\left(1 \mathrm{~m}^{2}\right)$ por piquete, as quais foram separadas em folha, caule e material morto.

As análises de proteína bruta foram feitas segundo ASSOCIATION OF OFFICIAL ANALYTICAL CHEMISTS - AOAC (1990); fibra detergente neutro, de acordo com GOERING e VAN SOEST (1970); e concentração de cromo nas fezes, como descrito por WILLIAMS et al. (1962), utilizando-se espectofotômetro de absorção atômica.

Para as análises do consumo diário de matéria seca, tempo de pastejo, conteúdo ruminal e ganho de peso diário dos animais, foi utilizado um modelo matemático contendo os efeitos fixos de tratamento, bloco, estação do ano e animais dentro de tratamento, além das interações simples entre si. As características das pastagens foram analisadas por um modelo matemático contendo os efeitos fixos de tratamento, bloco e estação do ano e as interações simples entre esses. Ainda foram estimadas as correlações entre as respostas do animal e as características das pastagens.

\section{Resultados e Discussão}

Não foi observada interação $(\mathrm{P}>0,43)$ entre cultivares e estação do ano para a disponibilidade de matéria seca total (MST). A despeito de o manejo adotado ter sido escolhido com o propósito de manter a mesma disponibilidade de forragem para todas as cultivares, foram observadas diferenças $(\mathrm{P}<0,01)$, sendo, em média, 1470,1910 e $2130 \mathrm{~kg} / \mathrm{ha}$ para os capins Colonião, Tobiatã e Tanzânia, respectivamente. Mesmo diminuindo a taxa de lotação durante o período seco, não foi possível manter a mesma $(\mathrm{P}<0,01)$ disponibilidade de MST, ao longo do ano. As médias para as três cultivares foram 1610 e $2060 \mathrm{~kg} / \mathrm{ha}$, para os períodos da seca e das águas, respectivamente.

Foram observadas interações $(\mathrm{P}<0,01)$ entre cultivares e período do ano para as porcentagens de material verde e de folhas e, conseqüentemente, para as disponibilidades de matéria verde seca (MVS) e de folhas, e relação material verde:material morto. Estes resultados são apresentados na Tabela 1. Como outras gramíneas tropicais, estas não crescem de maneira uniforme ao longo do ano. Isto é conseqüência de variações de temperatura, fotoperíodo e estacionalidade das chuvas, característica dessas regiões. De maneira geral, há excesso de produção no período das águas e escassez na seca. Além dessas variações nas taxas de crescimento da planta, existem alterações nas características morfológicas da pastagem. Durante a estação de crescimento, há acúmulo de material morto, associado à senescência natural da planta forrageira, acelerada por déficit hídrico, ou por geadas. Observa-se, ainda, acréscimo na proporção de caule em relação à quantidade de folha na pastagem (Tabela 1), o que resulta em variações qualitativas na dieta selecionada pelo animal em pastejo (Tabela 2).

Conseqüentemente, foram observadas interações $(\mathrm{P}<0,01)$ entre cultivares e período do ano, para as porcentagens de folhas e material verde presentes nas extrusas. Independentemente da variação observada entre a seletividade dos animais nas diferentes cultivares e período do ano, os animais preferiram consumir folhas a caules e forragem verde à morta (Tabelas 1 e 2). A proporção de folhas nas dietas 
selecionadas pelos animais decresceu durante o período seco, acompanhando a redução na disponibilidade desta fração (Tabela 1). No entanto, mesmo neste período, a participação de folhas na dieta selecionada pelo animal foi superior a $78 \%$. A quantidade de material morto constituiu apenas pequena proporção da dieta, em torno de $10 \%$ durante o período seco, e quantidades desprezíveis no período das águas. Con- seqüentemente, quando comparada com a forragem disponível, a dieta selecionada pelos animais apresentou maior valor nutritivo (EUCLIDES et al., 1992).

Também foram observadas interações $(\mathrm{P}<0,01)$ entre cultivares e período do ano para os conteúdos de PB, FDN e DISMS das dietas selecionadas pelos animais. Independentemente das variações observadas dentro das cultivares, o conteúdo de PB e a

Tabela 1 - Médias dos quadrados mínimos para as porcentagens de material verde e folha, disponibilidades de material verde e folha, relação material verde:material morto (mv:mm), e as taxas de lotação (TL) em pastagens de capins Colonião, Tobiatã e Tanzânia, sob pastejo contínuo

Table 1 - Least squares means for percentages of green matter and leaves, availabilities of green matter and lea, green matter:dead material ratio (gm:dm) and stocking rate (SR) in pastures of Colonião, Tobiatã and Tanzânia grasses

\begin{tabular}{|c|c|c|c|c|c|c|}
\hline & \multicolumn{2}{|c|}{ Colonião } & \multicolumn{2}{|c|}{ Tobiatã } & \multicolumn{2}{|c|}{ Tanzânia } \\
\hline & $\begin{array}{c}\text { Águas } \\
\text { Rainy } \\
\text { season }\end{array}$ & $\begin{array}{c}\text { Seca } \\
\text { Dry } \\
\text { season }\end{array}$ & $\begin{array}{c}\text { Águas } \\
\text { Rainy } \\
\text { season }\end{array}$ & $\begin{array}{c}\text { Seca } \\
\text { Dry } \\
\text { season }\end{array}$ & $\begin{array}{c}\text { Águas } \\
\text { Rainy } \\
\text { season }\end{array}$ & $\begin{array}{c}\text { Seca } \\
\text { Dry } \\
\text { season }\end{array}$ \\
\hline $\begin{array}{l}\text { Verde }(\%) \\
\text { Green }\end{array}$ & $68,8^{a}$ & $39,3^{\mathrm{b}}$ & $65,2^{\mathrm{a}}$ & $41,6^{b}$ & $73,3^{a}$ & $34,6^{b}$ \\
\hline $\begin{array}{l}\text { Folha }(\%) \\
\text { Leaf }\end{array}$ & $44,7^{\mathrm{a}}$ & $26,2^{b}$ & $47,0^{\mathrm{a}}$ & $28,6^{\mathrm{b}}$ & $52,8^{a}$ & $23,0^{\mathrm{b}}$ \\
\hline $\begin{array}{l}\text { Material verde }(\mathrm{kg} / \mathrm{MS} \bullet \mathrm{ha}) \\
\text { Green matter }(\mathrm{kg} / \mathrm{DM} \bullet \mathrm{ha})\end{array}$ & $1190^{\mathrm{a}}$ & $475^{b}$ & $1360^{\mathrm{a}}$ & $720^{b}$ & $1710^{\mathrm{a}}$ & $655^{b}$ \\
\hline $\begin{array}{l}\text { Folha }(\mathrm{kg} / \mathrm{MS} \bullet \mathrm{ha}) \\
\text { Leaf }(\mathrm{kg} / \mathrm{DM} \bullet \mathrm{ha})\end{array}$ & $770^{\mathrm{a}}$ & $315^{b}$ & $975^{\mathrm{a}}$ & $495^{b}$ & $1210^{\mathrm{a}}$ & $435^{b}$ \\
\hline $\begin{array}{l}\text { Relação mv:mm } \\
\text { Ratio gm:dm }\end{array}$ & $2,35^{\mathrm{a}}$ & $0,65^{b}$ & $1,89^{\mathrm{a}}$ & $0,72^{b}$ & $2,84^{\mathrm{a}}$ & $0,53^{b}$ \\
\hline $\begin{array}{l}\text { TL }\left(\mathrm{n}^{\mathrm{o}} \text { nov }^{*} / \mathrm{ha}\right) \\
\text { SR }(\text { n. steer } / \text { ha) }\end{array}$ & $2,7^{\mathrm{a}}$ & $2,0^{\mathrm{b}}$ & $3,9^{\mathrm{a}}$ & $2,7^{b}$ & $3,3^{\mathrm{a}}$ & $2,7^{b}$ \\
\hline
\end{tabular}

* Novilhos com PV médio de $300 \mathrm{~kg}$ (Steers with average $300 \mathrm{~kg}$ LW).

Médias, na linha e dentro de cultivares, seguidas de letras diferentes são diferentes $(P<0,01)$ pelo teste Tukey.

Means, within a row and among cultivars, followed by different letters are different $(P<.01)$ by Tukey test.

Tabela 2 - Médias dos quadrados mínimos para as porcentagens de material verde e folha, degradação in situ da matéria seca (DISMS), proteína bruta (PB) e fibra detergente neutro (FDN) das extrusas dos animais pastejando os capins Colonião, Tobiatã e Tanzânia

Table 2 - Least square means for percentages of green matter and leaves, in situ dry matter degradation (ISDMD), crude protein $(C P)$ and neutral detergent fiber (NDF) of extrusa from animals grazing Colonião, Tobiatã and Tanzânia grasses

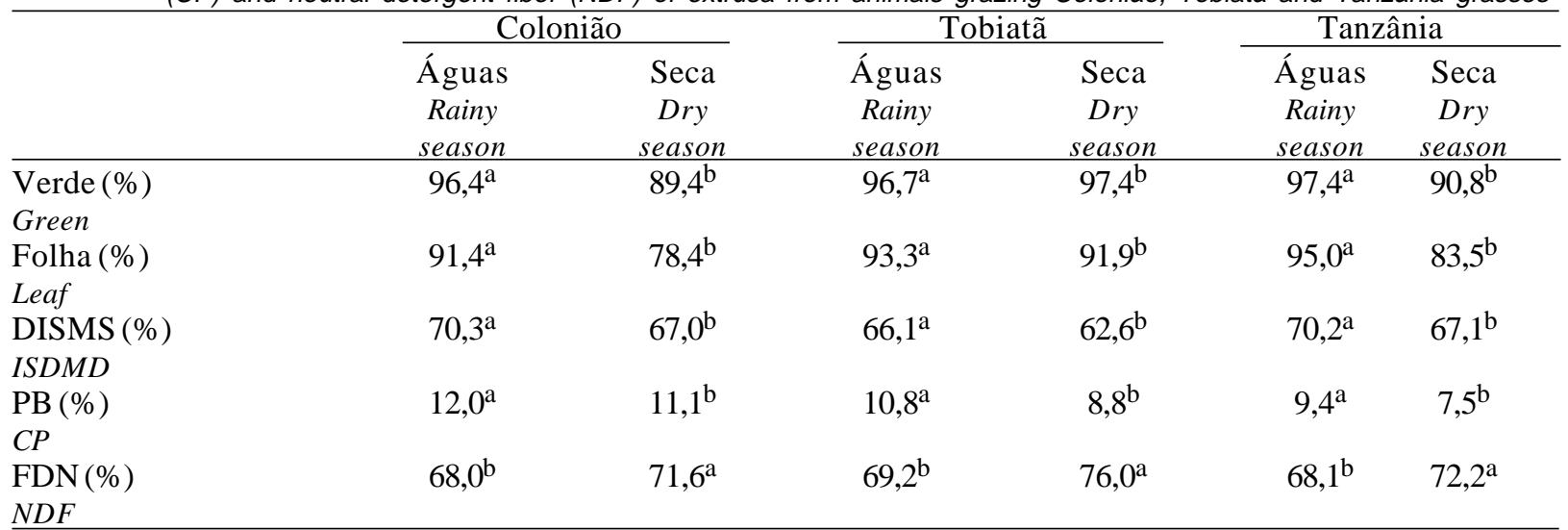

Médias, na linha e dentro de cultivares, seguidas de letras diferentes são diferentes $(\mathrm{P}<0,05)$ pelo teste Tukey.

Means, within a row and among cultivars, followed by different letters are different $(P<.05)$ by Tukey test. 
Rev. bras. zootec.

DISMS da dieta selecionada foi maior e a porcentagem de FDN, menor $(\mathrm{P}<0,05)$, durante o período das águas em relação ao da seca (Tabela 2).

As estimativas de CVMS foram semelhantes $(\mathrm{P}>0,19)$ entre os animais dentro dos tratamentos. Não foi observada diferença $(\mathrm{P}>0,66)$ para a excreção de cromo nas amostras de fezes coletadas pela manhã ou à tarde; dessa forma, para o cálculo da produção de fezes, foi utilizada a média das concentrações de cromo por novilho. A produção média de fezes foi de 0,87 e $0,71 \mathrm{~kg}$ de MS/ $100 \mathrm{~kg}$ de peso vivo, durante os períodos seco e das águas, respectivamente.

Quanto às variáveis consumo voluntário de matéria seca (CVMS), tempo de pastejo (TP), conteúdo ruminal de fibra detergente neutro (FDNr) e ganho de peso diário (GPD), nenhuma das interações analisadas foi significativa $(\mathrm{P}>0,33)$. Apesar de os CVMS pelos animais terem sido semelhantes $(\mathrm{P}>0,31)$ entre as cultivares, foram observadas diferenças $(\mathrm{P}<0,01)$ nos conteúdos FDNr, sendo maiores para os animais em pastagem de Tobiatã, seguidos, em ordem decrescente, por aqueles que se encontravam em pastagens de Colonião e de Tanzânia (Tabela 3). Isso provavelmente explica, em parte, os maiores $(\mathrm{P}<0,01)$ ganhos de peso observados nos animais pastejando o capim Tanzânia, seguidos daqueles que se encontravam nos capins Colonião e Tobiatã. Como não houve diferença no CVMS, é possível que diferenças no GPD tenham ocorrido em função de maiores taxas de saída da digesta do rúmen. De fato, as DISMS foram maiores $(\mathrm{P}<0,05)$ para as cvs. Tanzânia e Colonião, quando comparadas à cv. Tobiatã (Tabela 2). Foram também observadas diferenças $(\mathrm{P}<0,01)$ entre as cultivares para tempo de pastejo, que foi menor para os animais em pastagem de Tobiatã, quando comparados aos que pastejavam as outras duas cultivares (Tabela 3 ).

$\mathrm{O}$ ganho de peso e o CVMS pelos animais foram maiores $(\mathrm{P}<0,01)$ durante o período das águas, quando comparados aos do período seco (Tabela 4). Isso mostra que o efeito sazonal sobre estas variáveis foi maior que as variações entre as cultivares, o que confirma este aspecto como um ponto de estrangulamento dos sistemas de produção de carne com base em pastejo exclusivo (SMITH e DABORN, 1991).

Geralmente, quando o crescimento do animal é retardado em consequiência de subnutrição, este é capaz de se recuperar, apresentando ganho compensatório. WANYOIKE e HOLMES (1981), O'DONOVAN (1984)e RYAN (1990) mencionam aumento naingestão de alimentos após a finalização do período de restrição. Isso pode explicar os altos consumos de forragem pelos
Tabela 3 - Médias dos quadrados mínimos para consumo de matéria seca (CMS), conteúdo ruminal de fibra detergente neutro (FDNr), tempo de pastejo (TP) e ganho de peso diário (GPD) dos animais pastejando os capins Colonião, Tobiatã e Tanzânia

Table 3 - Least squares means for dry matter intake intake (DMI), ruminal content of neutral detergent fiber (NDFr), grazing time (GT) and daily weight gain (DWG) of animals grazing Colonião, Tobiatã and Tanzânia grasses

\begin{tabular}{lccc}
\hline & Colonião & Tobiatã & Tanzânia \\
\hline CMS $^{1}$ & $2,51^{\mathrm{a}}$ & $2,34^{\mathrm{a}}$ & $2,46^{\mathrm{a}}$ \\
$D M I$ & & & \\
$\mathrm{FDNr}^{1}$ & $0,80^{\mathrm{b}}$ & $0,86^{\mathrm{a}}$ & $0,72^{\mathrm{c}}$ \\
$N D F r$ & $537^{\mathrm{b}}$ & $561^{\mathrm{a}}$ \\
$\mathrm{TP}(\mathrm{min} / \mathrm{d})$ & $565^{\mathrm{a}}$ & $370^{\mathrm{b}}$ & $485^{\mathrm{a}}$ \\
$G T$ & & & \\
$\begin{array}{l}\mathrm{GPD} \text { (g/anim.d) } \\
D W G\end{array}$ & $390^{\mathrm{b}}$ & &
\end{tabular}

1 (kg/100kg PV) $(\mathrm{kg} / 100 \mathrm{~kg} L W)$.

Médias, na mesma linha, seguidas de letras diferentes são diferentes $(\mathrm{P}<0,05)$ pelo teste Tukey.

Means, in the same line, followed by different letters are different $(P<.05)$ by Tukey test.

animais, observados em novembro (Figura 1). Além disso, os animais utilizados neste experimento foram de sobreano, e consumos mais elevados são esperados em animais mais jovens. ARNOLD (1970) mostrou que, em condições de pastejo, ovelhas com seis meses de idade consumiram 60 a $100 \%$ a mais do que ovelhas com três anos de idade.

Apesar da tentativa de se igualar a disponibilidade de matéria seca entre cultivares e períodos do ano, pelo ajuste das taxas de lotação ao longo do ano, isto não foi possível (Tabela 1). Como conseqüência, houve queda no CVMS e no GPD durante o período seco (Tabela 4). Estes atingiram valores máximos no início da estação de rebrota e, então, decresceram gradualmente, apresentando os menores valores no final da estação seca (Figura 1). O inverso foi observado para o tempo de pastejo (Tabela 5), sugerindo tentativa de compensação por parte do animal e mostrando, dessa forma, que alguns ajustes na curva de suprimento de forragem e na curva de exigências nutricionais do rebanho podem ser feitas. Entretanto, onde ocorreu grande variação sazonal na produção de forragem, este ajuste não foi possível (Tabela 1).

Considerando que o consumo restrito (quantidade e/ou qualidade) de nutrientes é o principal fator limitando a produção animal, este só será controlado pelo valor nutritivo da forragem, se a quantidade de forragem disponível desta não for limitante. Entretan- 


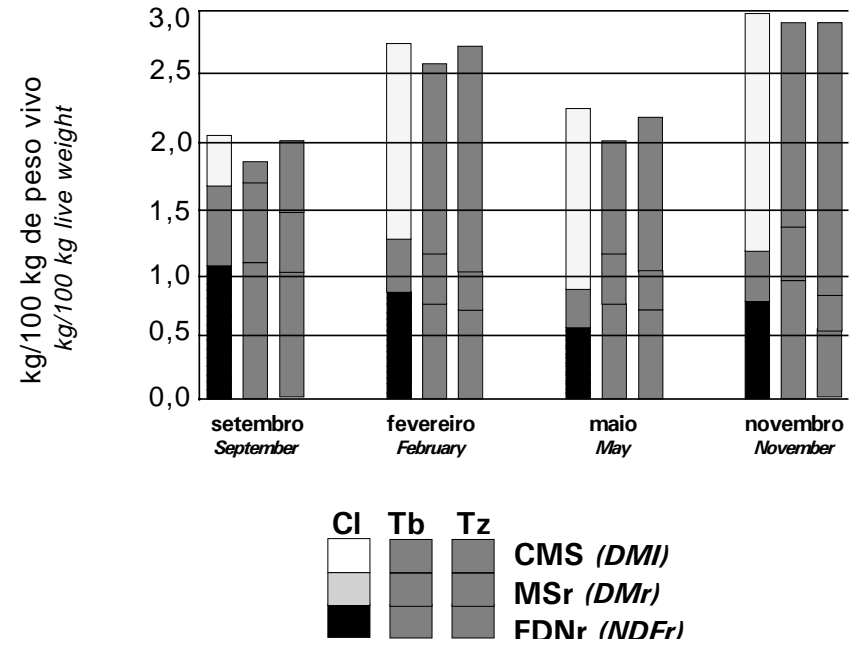

Figura 1- Médias dos quadrados mínimos para o consumo voluntário de matéria seca (CMS; kg/100 kg de peso vivo) e conteúdo ruminal de matéria seca (MSr; kg/100 kg de peso vivo) e fibra detergente neutro (FDNr; kg/100 kg de peso vivo) dos animais pastejando os capins Colonião, Tobiatã e Tanzânia.

Figure 1 - Least squares means for voluntary dry matter intake (DMI, kg/100 kg of live weight) and ruminal content of dry matter (DMr, $\mathrm{kg} / 100 \mathrm{~kg}$ of live weight) and neutral detergent fiber (NDFr, $\mathrm{kg} / 100 \mathrm{~kg}$ of live weight) from animals grazing Colonião, Tobiatã and Tanzânia grasses.

to, durante o período seco, as disponibilidades de MVS e de folhas, provavelmente, foram os fatores mais importantes limitando o consumo dos animais em pastejo (Tabelas 1 e 4) e, por conseguinte, restringindo o desempenho animal.

Existem vários fatores que influenciam o consumo, e os mecanismos que o regula não são completamente conhecidos (CONRAD, 1966; CAMPLING, 1970; WALDO, 1986; e MERTENS, 1994). A qualidade da forragem disponível geralmente tem grande influência na quantidade de forragem consumida pelos ruminantes. Sabe-se que deficiências de nutrientes específicos podem limitar o consumo (MINSON, 1990). Como os animais foram suplementados com sal mineral à vontade, pode-se assumir que o consumo não foi limitado pelos macro e microelementos. Da mesma forma, conteúdo de PB inferior a 6-7\% pode reduzir drasticamente o consumo (MILFORD e MINSON, 1966; MINSON e MILFORD, 1967). No entanto, os animais selecionaram dietas com conteúdos de PB acima deste valor crítico, mesmo durante o período seco (Tabela 2); dessa forma, a proteína
Tabela 4 - Médias dos quadrados mínimos para consumo voluntário de matéria seca (CVMS), conteúdo ruminal de fibra detergente neutro (FDNr), tempo de pastejo (TP) e ganho de peso diário (GPD) dos animais pastejando os capins Colonião, Tobiatã e Tanzânia, de acordo com período do ano

Table 4 - Least squares means for voluntary dry matter intake (DMI), ruminal content of neutral detergent fiber (NDFr), grazing time (GT) and daily weight gain (DWG) of animals grazing Colonião, Tobiatã and Tanzânia grasses, according to year

\begin{tabular}{lcc}
\hline & $\begin{array}{c}\text { Águas } \\
\text { Rainy season }\end{array}$ & $\begin{array}{c}\text { Seca } \\
\text { Dry season }\end{array}$ \\
\hline CVMS $^{1}$ & $2,82^{\mathrm{a}}$ & $2,05^{\mathrm{b}}$ \\
$V D M I$ & $0,74^{\mathrm{b}}$ & $0,84^{\mathrm{a}}$ \\
$\mathrm{FDNr}^{1}$ & $511^{\mathrm{b}}$ & $596^{\mathrm{a}}$ \\
$N D F r$ & $145^{\mathrm{b}}$ \\
$\mathrm{TP}(\mathrm{min} / \mathrm{d})$ & $683^{\mathrm{a}}$ & \\
$G T$ & & \\
$\mathrm{GPD}(\mathrm{g} /$ anim.d) & & \\
\hline
\end{tabular}

1 (kg/100kg PV) $(\mathrm{kg} / 100 \mathrm{~kg} \mathrm{LW})$

Médias, na mesma linha, seguidas de letras diferentes são diferentes $(\mathrm{P}<0,01)$ pelo teste Tukey.

Means, in the collumn, followed by different letters, are different $(P<0.01)$ by Tukey test.

não foi o fator limitante do consumo. Por outro lado, exceto para o Colonião durante o período das águas, os conteúdos de PB (Tabela 2) nas forragens (Tabela 2) não foram adequados para a produção máxima (Tabela 5), que, segundo ULYATT (1973), é de 12\% para todos os propósitos num rebanho de corte.

Isso pode ser comprovado pelo ganho médio de $680 \mathrm{~g} /$ dia obtido durante o período das águas, o qual, provavelmente, foi inferior ao potencial de ganho de peso, uma vez que animais retirados deste mesmo rebanho, quando confinados, apresentaram ganhos de 1100 g/dia (EUCLIDES et al., 1998). Considerando-se ainda que a quantidade de MVS disponível no período das águas não foi limitante (Tabela 1), conclui-se que o valor nutritivo destas forrageiras (Tabela 2) foi o fator que impossibilitou que esses animais atingissem seus potenciais de ganhos de peso.

Outro fator que limita o consumo é distensão física do retículo-rúmen, mecanismo de particular importância no caso das gramíneas tropicais, em consequiência dos seus altos conteúdos de FDN (BALCH e CAMPLING, 1962; VAN SOEST, 1982; 
Rev. bras. zootec.

e MINSON, 1990). MERTENS (1994) sugeriu que uma maneira quantitativa de se identificar o momento em que consumo é limitado pelo enchimento do rúmen (controle físico) é quando a ingestão de FDN é maior que $12 \mathrm{~g} / \mathrm{kg}$ PV. No presente trabalho, observaramse consumos médios de 14,5 e 19,0 g/kg PV de FDN, nos períodos da seca e águas, respectivamente. Essa diferença repercutiu em conteúdo ruminal de FDN maior para o período seco (Tabela 4, Figura 1), sugerindo menor taxa de degradação (Tabela 2) e, conseqüentemente, menor taxa de passagem, durante esse período. Nessa situação, correlação negativa entre consumo e conteúdo de FDN na forragem é esperada (Tabela 6). Entretanto, não foi observada correlação (Tabela 6) entre CVMS e FDNr, sugerindo que, exceto para o mês de setembro (Figura 1), outros fatores, que não o mecanismo de distensão, devem estar contribuindo para assinalar o término do primeiro período de pastejo diário. MERTENS (1994), com base em uma revisão de trabalhos sobre os mecanismos de controle de consumo de forragem, sugeriu que o controle da ingestão por mecanismos físicos e quimiostáticos pode se alternar dentro de um mesmo ciclo alimentar e, possivelmente, o mecanismo predominante no término de uma refeição individual seja diferente daquele que controla o consumo diário.

No entanto, sabe-se que o consumo dos animais em pastejo pode ser controlado por outros fatores associados ao manejo e/ou às características morfológicas inerentes das forrageiras, que influenciam a facilidade de preensão e seleção da forrageira (CHACON e STOBBS, 1976; COSGROVE, 1997). $\mathrm{O}$ tempo de pastejo (TP) foi maior $(\mathrm{P}<0,01)$ no período seco que no período das águas (Tabela 4). Em geral, o TP varia de 7 a 12 horas, e longo TP é indicativo de que o consumo está sendo limitado pelas características físicas da pastagem (Tabela 2), que dificultam a seleção e facilidade de preensão da forrageira. Isso pode ser confirmado pelas relações negativas entre TP e disponibilidades de MVS, de folhas, e da relação material verde:material morto, e positivas com a porcentagem de material morto (Tabela 6). Correlações semelhantes também foram observadas em vários experimentos com pastagens tropicais (STOBBS, 1973; HENDRICKSEN e MINSON, 1980; e EUCLIDES, 1985).

Sabe-se que, para selecionar uma dieta de maior valor nutritivo, os animais freqüentemente apreendem quantidades pequenas de forragem em cada bocada; conseqüentemente, há decréscimo na taxa de ingestão. No entanto, para manter consumo diário elevado, os animais tentam compensar aumentando o tempo de pastejo. Entretanto, neste trabalho, o aumento no TP observado durante o período da seca não foi suficiente para impedir queda no consumo de forragem neste mesmo período (Tabela 4). Dessa forma, além da disponibilidade de forragem, outras características da pastagem podem se tornar importantes, uma vez que a seleção da dieta é função da preferência pelos diferentes componentes da planta; no entanto, esta pode ser modificada à medida que as relações material verde:material morto e folha:caule passam a influenciar a oportunidade de seleção (Tabela 6).

O consumo voluntário de matéria seca foi correlacionado $\left(\mathrm{P}<0,01, \mathrm{r}^{2}=0,77\right)$ com o ganho diário de peso, confirmando que, entre as características das forragens, as de maior importância são aquelas que determinam o consumo voluntário de nutrientes. Neste trabalho, as características estruturais das pastagens - disponibilidade de folhas, porcentagem

Tabela 5 - Médias dos quadrados mínimos para tempo de pastejo (TP; minutos/dia) e ganho de peso diário (GPD; g/animal•dia) dos animais pastejando os capins Colonião, Tobiatã e Tanzânia

Table 5 - Least square means for grazing time (GT, minutes/day) and daily weight gain (DWG, g/animal•day) of animals grazing Colonião, Tobiatã and Tanzânia grasses

\begin{tabular}{|c|c|c|c|c|c|c|}
\hline & \multicolumn{2}{|c|}{ Colonião } & \multicolumn{2}{|c|}{ Tobiatã } & \multicolumn{2}{|c|}{ Tanzânia } \\
\hline & GPD & TP & GPD & $\mathrm{TP}$ & GPD & $\mathrm{TP}$ \\
\hline & $D W G$ & $G T$ & $D W G$ & $G T$ & $D W G$ & $G T$ \\
\hline Setembro & 15 & 620 & -20 & 634 & 158 & 608 \\
\hline September & & & & & & \\
\hline Fevereiro & 655 & 523 & 610 & 451 & 665 & 514 \\
\hline February & & & & & & \\
\hline Maio & 140 & 602 & 270 & 533 & 315 & 577 \\
\hline May & & & & & & \\
\hline $\begin{array}{l}\text { Novembro } \\
\text { November }\end{array}$ & 755 & 515 & 620 & 529 & 800 & 539 \\
\hline
\end{tabular}


EUCLIDES et al.

Tabela 6 - Correlação entre consumo de matéria seca, tempo de pastejo (TP) ganho de peso diário (GPD) e algumas características das gramíneas Colonião, Tobiatã e Tanzânia

Table 6 - Correlation among dry matter intake, grazing time (GT), daily weight gain (DWG) and some characterístics of Colonião, Tobiatã, and Tanzânia grasses

\begin{tabular}{lccc}
\hline & $\begin{array}{c}\text { Consumo } \\
\text { Intake }\end{array}$ & TP & GPD \\
\hline GPD & $0,77^{* *}$ & $-0,51^{* *}$ & \\
$D W G$ & $-0,62^{* *}$ & & $-0,51^{* *}$ \\
TP & $0,50^{* *}$ & & $0,68^{* *}$ \\
DISMS & & $0,39^{* *}$ \\
$\begin{array}{l}\text { ISDMD } \\
\text { PB }^{2}\end{array}$ & $0,47^{* *}$ & & $-0,47^{* *}$ \\
$C P$ & $-0,65^{* *}$ & & $0,47^{* *}$ \\
FDN & 0,29 & & $0,75^{* *}$ \\
$N D F$ & $-0,38^{* *}$ & $0,75^{* *}$ \\
$\begin{array}{l}\text { Disponibilidade MS } \\
\text { DM availability }\end{array}$ & $0,57^{* *}$ & $-0,55^{* *}$ & $0,36^{* *}$ \\
$\begin{array}{l}\text { Disponibilidade MSV } \\
\text { GDM availability }\end{array}$ & $0,73^{* *}$ & $-0,59^{* *}$ & $-0,80^{* *}$ \\
$\begin{array}{l}\text { Disponibilidade folha } \\
\text { Leafavailability }\end{array}$ & $0,62^{* *}$ & $-0,38^{* *}$ & $0,55^{* *}$ \\
$\begin{array}{l}\text { Porcentagem de folha } \\
\text { Leafpercentage }\end{array}$ & $-0,67^{* *}$ & $0,60^{* *}$ & $-0,04^{* *}$ \\
$\begin{array}{l}\text { Porcentagem de material morto } \\
\text { Percentage of dead material }\end{array}$ & $0,64^{* *}$ & $-0,65^{* *}$ & \\
$\begin{array}{l}\text { Relação material verde: material morto } \\
\text { Green material:dead material ratio }\end{array}$ & $-0,12$ & 0,40 & \\
$\begin{array}{l}\text { Conteúdo ruminal FDN } \\
\text { NDF ruminal content }\end{array}$ & & & \\
\hline
\end{tabular}

${ }^{* *} \mathrm{P}<0,01$

1 Digestibilidade in situ da matéria seca (In situ dry matter digestibily).

2 Proteína bruta (Crude protein).

${ }^{3}$ Fibra detergente neutro (Neutral detergent fiber).

4 Matéria seca (Dry matter).

5 Matéria seca verde (Green dry matter).

de folha e de material morto e relação material verde: material morto - influenciaram mais o CVMS, ganho de peso diário e o TP que os valores nutritivos das mesmas (Tabela 6).

\section{Conclusões}

O consumo voluntário de matéria seca foi altamente correlacionado com ganho de peso diário.

Os ganhos de peso diários foram maiores para os animais pastejando a cv. Tanzânia.

Os consumos de matéria seca foram semelhantes entre as cultivares de P. maximum. Apesar de os animais terem aumentado o tempo de pastejo durante o período da seca, este não foi suficiente para impedir queda na ingestão de forragem pelos animais, nesse período.

As características estruturais - disponibilidade de folhas e relação material verde:material morto das pastagens - foram correlacionadas com consumo voluntário, tempo de pastejo e ganho de peso diário dos animais.

Além das características estruturais dessas pas- tagens influenciando o consumo voluntário, este também foi correlacionado com o conteúdo de FDN.

\section{Referências Bibliográficas}

ASSOCIATION OF OFFICIAL ANALYTICAL CHEMISTS AOAC. 1990. Official methods of analyses. Arlington, v.1, p.72-74.

ARNOLD, G.W.1970. Regulation of food intake in granzing ruminants. In: PHILLIPSON, A.T. Phisiology of digestion and metabolism in the ruminant. Newcastle upon Tyne, England: Oriel. p.264-276.

BALCH, C.C., CAMPLING, R.C. 1962. Regulation of voluntary intake in ruminants. Nutr. Abstr. Rev., 32(3):669-686.

BURNS, J.C., POND, K.R., FISHER, D.S. 1994. Measurements of forage intake. In: FAHEY JR., G.C. Forage quality evaluation and utilization. Madison: American Society of Agronomy/Crop Science Society of America/Soil Science Society of America. p.494-531.

CAMPLING, R.C. 1970. Physical regulation of voluntary intake. In: PHILLIPSON, A.T. Physiology of digestion and metabolism in the ruminant. Newcastle upon Tyne, England: Oriel. p.226-234.

CONRAD, H.R. 1966. Symposium on factors influencing the voluntary intake of herbage by ruminants: physiological and physical factors limiting intake. J. Anim. Sci., 25(1):227-235. 
Rev. bras. zootec.

CHACON, E., STOBBS, T.H. 1976. Influence of progressive defoliation of grass sward on the eating behaviour of cattle. Austr. J. Agric. Res., 27(5):702-727.

COSGROVE, G.P. Grazing behaviour and forage intake. In: INTERNATIONAL SYMPOSIUM ON ANIMAL PRODUCTION UNDER GRAZING, 1997, Viçosa. Anais... Viçosa: UFV, 1997. p.59-80.

EUCLIDES, V.P.B. Quality evaluation and cattle grazing behavior on bahiagrass and limpograss pastures. Gainesville: University of Florida, 1985. 176p. Thesis (Doctor) University of Florida, 1985.

EUCLIDES, V.P.B., EUCLIDES FILHO, K., ARRUDA, Z.J. et al. 1998. Desempenho de novilhos em pastagens de Brachiaria decumbens submetidos a diferentes regimes alimentares. $R$. Bras. Zootec., 27(2):246-254.

EUCLIDES, V.P.B., MACEDO, M.C.M., OLIVEIRA, M.P. 1992. Avaliação de diferentes métodos de amostragem para se estimar o valor nutritivo de forragens sob pastejo. R. Soc. Bras. Zootec., 21(4):691-702.

EUCLIDES, V.P.B., MACEDO, M.C.M., OLIVEIRA, M.P. In: INTERNATIONAL GRASSLAND CONGRESS, 18, 1997. Proceedings... Winnnipeg, Saskatoon, Canada, 1997. v. 2, p. 111-112.

EUCLIDES, V.P.B., MACEDO, M.C.M., VIEIRA, et al. In: INTERNATIONAL GRASSLAND CONGRESS, 17, 1993. Rockhampton. Proceedings...Palmerston North: New Zealand Grassland Association, 1993. p.1999-2000.

GOERING, H.K., VAN SOEST, P.J. 1970. Forage fiber analyses, apparatus, reagents, procedures and some applications. Washington, DC: USDA (Agricultural Handbook, 379).

HENDRICKSEN, R.E., MINSON, D.J. 1980. The feed intake and grazing behaviour of cattle grazing a crop of Lablab purpureus cv. Rongai. J. Agric. Sci., 5(4):547-554.

MANNETJE, L.t', JONAS, R.J., STOBBS, T.H. 1976. Pastures evaluation by grazing experiments. In: SHAW, N.H., BRYAN, W.W. Tropical pastures research: principles and methods. Farnham Royal: CAB, p.194-234.

MERTENS, D.R. 1994. Regulation of forage intake. In: FAHEY JR., G.C. (Ed.). Forage quality evaluation and utilization. Madison: American Society of Agronomy/Crop Science Society of America/Soil Science Society of America, p.450-493.

MILFORD, R., MINSON, D.J. Intake of tropical pasture species In: CONGRESSO INTERNATIONAL DE PASTAGEM, 9, 1965, São Paulo. Anais... São Paulo: Secretaria de Agricultura, 1966. p.814-822.

MINSON, D.J. 1971. The digestibility and voluntary intake of six varieties of panicum. Austr. J. Experim. Agric. Anim. Husb., 11(48):18-25.

MINSON, D.J. 1990. Forage in ruminant nutrition. San Diego: Academic Press. 483p.

MINSON, D.J., MILFORD, R. 1967. The voluntary intake and digestibility od diets containing different proportions of legume and mature pangola grass (Digitaria decumbens).
Austr. J. Exper. Agric. Anim. Husb., 7(29):546-551.

O'DONOVAN, P.B. 1984. Compensatory gain in cattle and sheep. Nutr. Abstr. Rev., Series B, 54(8):389-410.

RYAN, W.J. 1990. Compensatory growth in cattle and sheep. Nutr. Abstr. Rev., Series B, 60(10):653-664.

SMITH, A.J., DABORN, C.J. 1991. Constraints to animal production and health in the tropics. In: HUNTER, A.G. Biotechnology in livestock in developing countries. Proceedings of Biotechnology. Edinburgh: University of Edinburgh. p.2-18.

STOBBS, T.H. 1973. The effect of plant structure on the intake of tropical pastures. II. Differences in sward structure, nutritive value, and bite size of animals grazing Setaria anceps and Chloris gayana at various stages of growth. Austr. J. Agric. Res., 24(6):821-829.

TILLEY, J.M.A., TERRY, R.A. 1963. A two stage technique for the in vitro digestion of forage crops. J. Brit. Grassl. Soc., 18(2):104-111.

THORNTON, R.F., MINSON, D.J. 1973. The relationship between apparent retention time in the rumen, voluntary intake and apparent digestibility of legume and grass diets in sheep. Austr. J. Agric. Res., 24(6):889-898.

ULYATT, M.J. 1973. The feeding value of herbage. In: BUTLER, G.W., Bailey, R.W. Chemistry and biochemistry of herbage. London: Academic Press, v.3, p.131-178.

VAN SOEST, P.J. 1983. Nutritional ecology of the ruminant. Corvalis: O \& B Books. 374p.

WALDO, D.R. 1986. Effect of forage quality on intake and forageconcentrate interactions. J. Dairy Sci., 69(4):617-631.

WANYOIKE, M.M., HOLMES, H. 1981. The effects of winter nutrition on the subsequent live-weight performance and intake of herbage by beef cattle. J. Agric. Sci., 97(1):221-226.

WILLIAMS, C.H., DAVID, D.J., ISMAA, O. 1962. The determination of chromic oxide in faeces samples by atomic absortion spectrophotometry. J. Agric. Sci., 59(3):381-385.

Recebido em: 07/12/98 Aceito em: 13/04/99 